\title{
La imagen en el contexto de la violencia en Colombia: un acercamiento a distintas perspectivas*
}

\author{
THE IMAGE IN THE CONTEXT OF THE VIOLENCE IN COLOMBIA: AN APPROACH \\ TO DIFFERENT PERSPECTIVES
}

A IMAGEM NO CONTEXTO DA VIOLÊNCIA NA COLÔMBIA: UMA

APROXIMAÇÃO A DISTINTAS PERSPECTIVAS

\section{Etna Castaño Giraldo** \\ Alejandra Avella Estrada*** \\ Alejandra Arango Murcia**** Carlos Sánchez*****}

Cuadernos de Música, Artes Visuales y Artes Escénicas

/ Volumen 11 - Número 1 / enero - junio de 2016

/ ISSN 1794-6670/ Bogotá, D.C., Colombia / pp. 151-163

Fecha de recepción: 15 de mayo de 2015 | Fecha de aceptación: 26 de septiembre de 2015 | Disponible en línea: 30 de mayo de 2016. Encuentre este artículo en

http://cuadernosmusicayartes.javeriana.edu.co/

doi:10.11144/Javeriana.mavae11-1.icvc

* Artículo de investigación. Balances del proyecto de investigación Imagen, violencia política y formación. CIUP. Universidad Pedagógica Nacional.

** Maestra en Artes Plásticas. Investigadora y docente de la Licenciatura en Artes Visuales de la Universidad Pedagógica Nacional.

** Licenciada en Artes Visuales de la Universidad Pedagógica Nacional. Profesional de apoyo académico del proyecto investigativo.

*** Licenciada en Psicología y Pedagogía. Universidad Pedagógica Nacional. Monitora de investigación del proyecto, adscrita al Centro de Investigaciones de la Universidad Pedagógica - CIUP.

**** Licenciado en Psicología y Pedagogía. Universidad Pedagógica Nacional. Monitor de investigación del proyecto, adscrito al Centro de Investigaciones de la Universidad Pedagógica - CIUP. 


\section{Resumen}

El presente artículo hace parte de los avances del proyecto de investigación Imagen, violencia política y formación: perspectivas de análisis en Colombia, adscrito al centro de investigaciones de la Universidad Pedagógica Nacional; el cual tuvo como propósito llevar a cabo un estado del arte de los estudios sobre el lugar de la imagen en relación con la violencia política en Colombia. En este artículo se presenta el trabajo de varios autores que entre los años 2000 y 2010 han adelantado investigaciones en torno a dos categorías de análisis: imagen y violencia; para finalmente señalar rasgos comunes entre distintas perspectivas que ofrecen formas de comprensión de la imagen y su vínculo con la violencia política en el contexto colombiano.

Palabras claves: imagen; violencia; cuerpo; memoria; discurso

\section{Abstract}

This paper is part of the project Image, political violence and training: analytical perspectives in Colombia, associated with the Research Center of the Universidad Pedagógica Nacional. The purpose of this study is to carry out a state of the art of studies about the role of the image in relation to political violence in Colombia. In this article is presented the work of several authors that between 2000 and 2010 have advanced research on two categories of analysis: image and violence; finally, the research shows common elements between different perspectives that offer ways of understanding image and its link to the political violence in the Colombian context.

Keywords: image; violence; body; memory; discourse

\section{Resumo}

Este artigo é parte do progresso da projeto de pesquisa, Imagem, violência política e a formação: perspectivas analíticas na Colômbia, parte do Centro da Investigação da Universidade Pedagógica Nacional; que tinha como objetivo a realização de um estado da arte dos estudos sobre o papel da imagem em relação à violência política na Colômbia. Neste artigo, o trabalho de vários autores que, entre 2000 e 2010, têm avançado de pesquisa em duas categorias de análise é apresentada: Imagem e violência; finalmente, assinalando semelhanças entre diferentes perspectivas que oferecem formas de compreensão da imagem e sua ligação com a violência política no contexto colombiano.

Palavras-chave: imagem; violência; corpo; memória 


\section{NOTAS DE AUTOR}

Previa escritura de este artículo, se ha llevado a cabo la revisión de una serie de documentos producidos en Colombia, entre 2000 y 2010, que han pensado la imagen como escenario alterno para el estudio de la violencia y donde se reconfiguran algunas comprensiones sobre lo violento, desde una perspectiva de construcción de Memoria y reivindicación del otro. De este ejercicio investigativo surgió la necesidad de mostrar la postura de algunos autores que han trabajado la imagen como una forma de resignificación de la violencia.

Actualmente en Colombia algunos estudios sobre la imagen se han preocupado por rastrear los vínculos ontológicos que las imágenes han tejido con el fenómeno de la violencia política y algunos campos del saber, como el arte, la historia, la antropología, y la sociología. Nos referimos concretamente al fenómeno de la violencia política como elemento constitutivo de las identidades colectivas, las cuales han contribuido a la configuración de subjetividades singulares, ancladas a procesos de distinta índole en el marco del conflicto.

En un acercamiento a distintos documentos incluidos en el estado del arte del proyecto de investigación del que este artículo emerge, ${ }^{1}$ se ha observado que la imagen aparece como representación de un fenómeno —el de la violencia política- desde múltiples "usos", bien desde el lugar del victimario o del lado de la víctima. En este último, encarnando el relato de memoria colectiva sin que - como se evidenciará más adelante- se profundice en asuntos relacionados con la imagen como síntesis de una práctica y un discurso, pues esta se nutre de lecturas que hasta el momento se han basado en la naturalización de la violencia como parte estructural del devenir histórico del país.

Hoy se sabe de la potencia narrativa que contiene la imagen en su interior, la cual se constituye como lenguaje en la medida en que nos habla y nos dice sobre algo, en este caso sobre la violencia. De allí que se considere de primer orden que los estudios que han buscado en la imagen lugares para establecer puntos de referencia que conduzcan a la comprensión de las acciones humanas, deban procurar que los instrumentos de observación, estudio y análisis de la imagen y su relación con la violencia política, nos ayuden a elaborar de manera colectiva una idea acerca de las causas y los orígenes del conflicto. Pero también permitan reconocer nuestra responsabilidad y compromiso en la búsqueda de alternativas que le pongan fin a las acciones de violencia, ya aparentemente naturalizadas en el contexto nacional.

De esa manera, para adentrarnos en la presentación y descripción de los hallazgos del estado del arte realizado en el marco de la investigación aquí referenciada, hemos de valernos de categorías que los textos documentados nos han proporcionado como sistemas análogos a los desarrollos teóricos que, en distintos niveles, cada uno de ellos ha elaborado. Por lo tanto, dichas categorías no deben entenderse como sobre-interpretaciones de los autores de este artículo, quienes intentan dejar ser y aparecer las formas de enunciación acerca de la relaciones entre imagen y violencia política que los documentos han evidenciado a la luz de una diversidad de enfoques; que para este caso no problematizaremos, sino que interesa identificar las formas de lo dicho y comprendido, para cartografiar las posibles distancias y conexiones entre esas lecturas. 


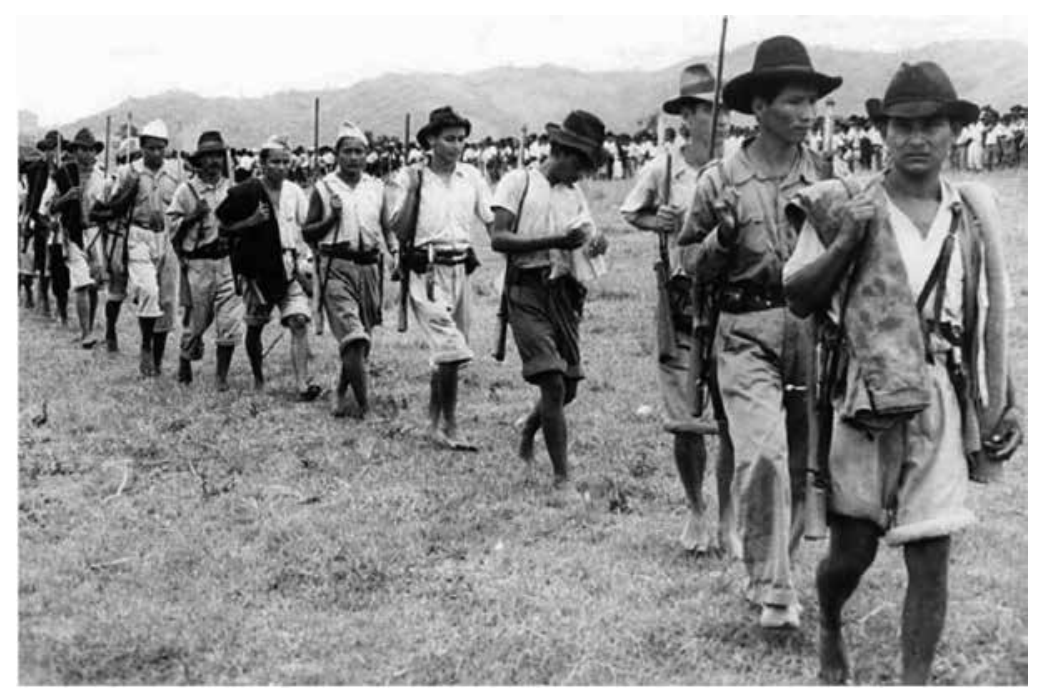

Imagen 1. Fotografía publicada por el diario El Espectador en su página web: "60 años de violencia política en el país"2.

\section{A MANERA DE HALLAZGOS...}

\section{Sobre el carácter comunicativo de la imagen}

De los trabajos que desarrollan estudios acerca de la imagen y la violencia política en Colombia, se encuentra la producción de María Margarita Malagon-Kurka (2010), quien al acercarse a las obras de Beatriz González, Oscar Muñoz y Doris Salcedo, identifica que los artistas han tomado el fenómeno de la violencia en Colombia como elemento para la creación.

Al hacer un recorrido que relaciona las obras de los diferentes artistas, la autora analiza las maneras en las que estas se relacionan y hablan de la violencia, en tanto la imagen del arte emerge como un canal de comunicación que dice de lo violento. En esa medida, la imagen adquiere un carácter comunicativo que se funda en la veracidad y la inmediatez. Así por ejemplo, la autora señala que en los años cincuenta en Colombia, la violencia se mostraba de forma visceral, trágica y fragmentada, pues se creía que el impacto era mayor cuando la imagen mostraba condiciones más cercanas a lo real o mostraba la violencia misma; por el contrario, en los años noventa el uso de la imagen se concentró en el simbolismo de lo que la violencia erradicó, esto es, los asuntos colaterales a los actos violentos.

En lo anterior, es posible identificar el carácter verídico e inmediato de la imagen en sus formas de mostrar y hablar de lo violento; sin embargo, la veracidad depende de una dimensión histórica, la cual delimita las intencionalidades particulares de una época, y por tanto, de los sujetos. Como se logra evidenciar, la imagen en el tiempo, ligada a su intencionalidad comunicativa, se transforma en sus modos de aparecer, pero también en las vías en las que se muestra; es decir, lo que comunica y cómo lo comunica.

Es así como Malagon-Kurka (2010), diferencia la imagen que tiene lugar en lo artístico de la de los medios de comunicación, señalando que la imagen de los medios —paradójicamente- es usada para informar parte de un fenómeno y reducirlo de su "verdadera" dimensión. Por su parte, la imagen que deviene de lo artístico comunica en consecuencia con el recuerdo, y con una intencionalidad enmarcada en la memoria de los acontecimientos violentos. 
De esta manera, la imagen que deviene de las diferentes prácticas artísticas otorga al fenómeno de la violencia características que ayudan a comprenderlo de manera diversa; esto es, en un intento por deslegitimar la forma unívoca de entender la violencia que se ha instaurado poco a poco desde los medios de comunicación, donde se invisibiliza este fenómeno al punto de la indiferencia y la indolencia. Así, se trata de reconocer que el efecto de la imagen depende de la intencionalidad que subyace; un efecto que según Malagon-Kurka (2010), debe ser comunicativo, en términos de apostarle a otras formas de hablar y abordar la violencia.

Por su parte, Charles Merewether (1993) analiza las formas de representación visual, evidenciando que la imagen, particularmente la fotográfica, da lugar a dos intencionalidades: fotografía periodística y fotografía personal. La fotografía periodística es desde la cual se quiere mostrar en el plano público las imágenes producidas en el marco del conflicto armado, donde se hace evidente la muerte, el dolor y muchas veces la ausencia de los cuerpos. De otro lado, la fotografía personal se da en el plano de lo privado, en el cual se le atribuye importancia a los retratos realizados por las madres y familiares de las víctimas.

En esa medida, Merewether (1993) tomando la obra y el devenir artístico de Doris Salcedo, señala que la artista hace uso de otras representaciones visuales, como la fotografía (personal y periodística), ubicando la imagen en términos de posibilidad para la construcción de sentido a partir del vínculo que se genera entre la esfera privada — propia de las víctimas y los artistas- y la esfera pública —-medios de comunicación y museos.

A la luz del análisis de la obra de Salcedo, el autor menciona que la imagen se muestra como una forma intencional, no sólo de alejar al espectador del espectáculo mediático de la violencia colombiana, sino también de afectarlo e invitarlo a sensibilizarse ante el sufrimiento de la víctima, lo cual conduce al reconocimiento del otro. Desde lo anterior, es posible atribuirle a la imagen como rasgo característico, la representación que hace de la realidad y el interés por denunciar hechos violentos de nuestra historia que no siempre han sido reconocidos en la esfera pública; encontrando que la imagen, en algunos trabajos ${ }^{3}$ y prácticas artísticas, recurre a la violencia como insumo que permite el surgimiento de la obra.

En consecuencia, Merewether (1993) nos dice:

Las formas de representación visual asumen una importante función ideológica (...) la importancia de llevar a las calles las fotografías de los desaparecidos o de las personas asesinadas es que estos retratos representan a los muertos y no a la muerte. Su poder deriva de la forma de resurrección obtenida en el acto de mostrar públicamente estos retratos íntimos, en la unión con los vivos y en el negarse a aceptar el anonimato de lo público. (pp. 104-105)

Así, cuando se habla de una imagen con relación a la violencia, se identifican distintas prácticas —en este caso, la obra plástica y la fotografía - donde a la representación visual de cada una de estas, le supone una intencionalidad comunicativa e ideológica. Dichas intencionalidades se vinculan con el fin de alcanzar y perpetuar una idea sobre lo violento con la imagen como herramienta; aquí el carácter ideológico antecede y determina al carácter comunicativo, pues como hemos visto, de la imagen se ha hecho uso desde el lugar de las víctimas, los victimarios, las instituciones, y por supuesto, los artistas, quienes para este caso, expresan en sus obras no solo la intención de dar cuenta de un fenómeno como la violencia, sino también una posición política frente a ella. 
Para autores como Luisa Fernanda Ordóñez (2013) la violencia se define como todas aquellas masacres que han marcado la historia del país, "donde la violencia explícita y la legitimidad del narcotráfico como esquema de posicionamiento social refuerzan una imagen brutal de la nación colombiana" (Ordóñez, 2013, p. 6), pero al tiempo, se ha convertido en material de inspiración para una serie de directores de cine colombiano que han visto en los cortometrajes y largometrajes, un potencial para la representación del conflicto armado en Colombia. Esta modalidad tuvo una gran eclosión después de la aparición de la Ley de cine, provocando que este medio audiovisual se convirtiera, a partir de ese momento, en uno de los soportes de carácter realista con fines de conservación de la memoria histórica del país.

Para acompañar su reflexión teórica, Ordóñez (2013) emplea las producciones del Centro de Memoria Histórica, ${ }^{4}$ como No hubo tiempo para la tristeza ${ }^{5}$ y Fábulas de tierras y memoria, ${ }^{6}$ entre otros, para afirmar que la imagen funciona para esta organización como herramienta de comunicación y denuncia de la violación de los derechos humanos en el conflicto colombiano. Otras de las imágenes estudiadas por la autora tienen que ver con las producciones fílmicas que se realizaron después de la Ley de cine, a propósito de lo cual señala:

Este nuevo cine colombiano, patrocinado por la Ley de cine de 2003 y el Fondo de Desarrollo Cinematográfico como organismo subsidiario, se ha caracterizado en gran parte por el recurso de un lenguaje contemplativo, el uso de actores naturales, y la presencia del paisaje colombiano fotografiado con una factura impecable; estos elementos entran en tensión con la contrariedad de presentar en imágenes la contundencia de la realidad colombiana. (Ordóñez, 2013, p. 8)

Al realizar un análisis de las distintas obras audiovisuales, Ordóñez (2013) insiste en que aún quedan asuntos por resolver y el que más preocupa a la autora es el relacionado con la presentación del victimario como protagonista y víctima, por lo que entonces quedarían justificados sus actos de extrema violencia para con otros, demostrando una vez más la falta de compromiso de estos medios con respecto a las víctimas directas y sus familias.

Como se observa, la autora atribuye una fuerza enorme a "la imagen como una potencial constructora de conocimiento histórico" (Ordóñez, 2013, p. 6) por lo que argumenta que la imagen mejor producida podría ayudar a contrarrestar el boom mediático que han aprovechado algunos directores para hacer de la violencia otro negocio más, sin el mínimo respeto por el dolor de todos los colombianos, que han padecido en carne propia los horrores de esta violencia. De esta manera, Ordóñez (2013) afirma que:

Este boom de producciones puede no ser gratuito, pues emergen precisamente un año después de la terminación de un periodo de gobierno que durante ocho años eludió el hecho flagrante de que en este país existía un conflicto armado interno. (p. 5)

Finalmente, la autora otorga a la imagen una función concreta relacionada con su potencial como constructora de conocimiento histórico, de manera que se instala en los ámbitos de reflexión acerca de la violencia en Colombia, como material verídico para el estudio de los fenómenos de violencia que han signado la historia del país en los últimos años. 


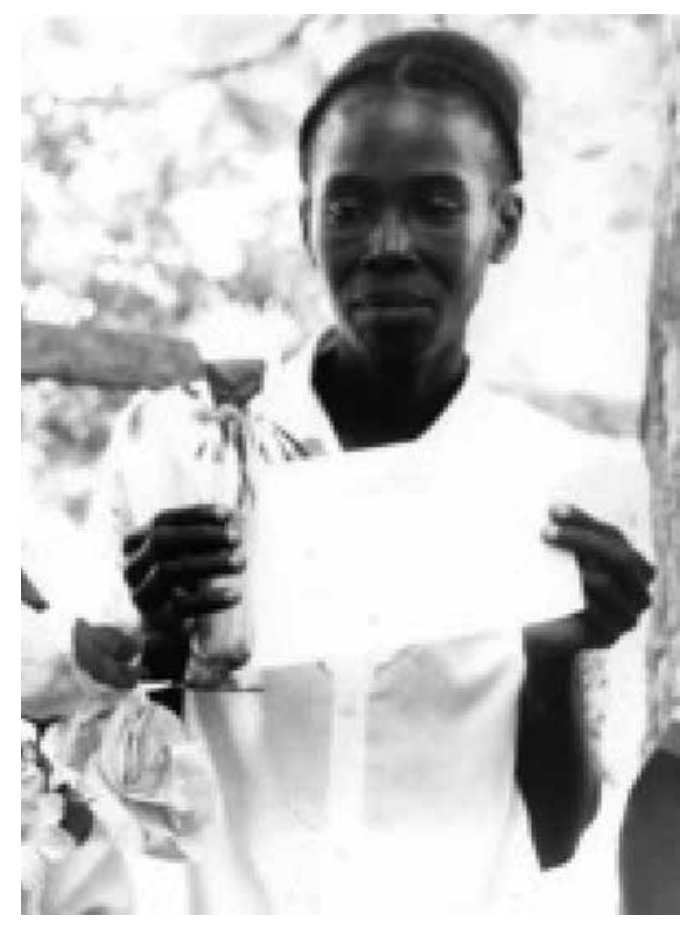

Imagen 2. Martha Palma. Personaje principal del documental "Una casa sola se vence" realizado por Martha Rodríguez?.

Por otro lado, Entre el color y el terror, un texto producido por el historiador colombiano Hermes Tovar Pinzón (2003), aborda temas como la violencia desde una perspectiva histórica que centra su mirada en algunas obras de pintura colombiana, entre ellas, las de Fernando Botero, uno de los pintores colombianos más conocidos en el contexto mundial, que ha trabajado desde la pintura el tema de la violencia.

A partir del análisis a la obra de este artista, Tovar (2003) enuncia que la imagen es vista como una forma de expresión y denuncia sobre algunos de los sucesos violentos que han caracterizado la historia del conflicto armado en Colombia. En ese sentido, la imagen es entendida como documento histórico que muestra desde la perspectiva artística, otra manera de acercarse a la comprensión de la realidad, para el caso, desde el plano de lo estético y lo poético, con lo cual se da lugar a la sensibilización sobre la condición humana; en ese sentido la imagen se constituye como otra forma de escribir la historia de nuestro país.

Para el autor, las obras de Botero buscan hacer posible una reflexión, y en esa vía, una posición ética y política respecto a los acontecimientos violentos sucedidos en Colombia. Lo anterior, dado que la pintura se convierte en una forma de expresión en donde cada artista reinterpreta, desde una visión muy personal, estos sucesos, posibilitando una re-significación del sufrimiento y el anhelo del cambio.

\section{Sobre imagen y su relación con el cuerpo}

Sandra Johana Silva-Cañaveral (2012) señala que:

El cuerpo, no sólo [puede ser] considerado como elemento inmediato sobre el que recae la violencia, sino también como imagen, es el lugar en el que se reafirma la experiencia del dolor y la superficie sobre la cual se escribe la historia. (p. 47) 
Son los cuerpos, las imágenes donde convergen la ideología, la violencia, el arte y la muerte, son imágenes que se comprenden desde el lugar de quien ejerce y vive un acontecimiento, pero tienen la pretensión de trascender y mostrarse en relación con lo cotidiano. Es ese el objetivo de la imagen artística según la autora, que apoyada en relatos de las víctimas, en la investigación y en la intención personal del artista por denunciar y hacer memoria, comunica un mensaje que pretende trasgredir las subjetividades y posibilitar una mirada distinta sobre los acontecimientos.

Así, la imagen en sí misma se comprende entonces como sospecha, resistencia y denuncia, se vuelve una herramienta artística que con el uso o representación del cuerpo, busca proporcionar otras formas de entender y comunicar lo pasado, lo que se debe recordar. Es en ese marco de comprensión, cuando Silva-Cañaveral (2012) afirma que la imagen:

(...) aparece como un dispositivo por medio del cual nombra, señala y resignifica la realidad.

[...] el artista puede reconocer en su quehacer un instrumento político y relacional con el que comunica una posición (de rechazo, fascinación, repudio, ironía, juego o afirmación), que legitima y devela en su proceso de creación la experiencia privada y el estado del fenómeno. (p. 55)

La autora sostiene que la imagen — cuando se detiene a pensar la violencia — se convierte en un vehículo de la memoria, el cual se fundamenta en políticas del no-olvido, en la medida en que investiga, muestra y le da un lugar al otro y su experiencia. Se trata entonces de situar a las víctimas y otorgarles una voz, una imagen, la cual se encuentra en el cuerpo de las víctimas, y la producción artística, que relacionadas dan paso a la representación simbólica de las obras; esto es, a otra alternativa para el recuerdo.

En esa medida, cabe considerar, desde la perspectiva de la imagen y su vínculo con la violencia ejercida sobre el cuerpo, al artista Fernando Pertuz (2007), quien pone en diálogo diferentes performances en los que encuentran elementos críticos y reflexivos acerca del fenómeno de la violencia, sobre todo a partir de la referencia y el uso del cuerpo. Para el autor, los performances hablan de violencia desde y hacia el cuerpo, ${ }^{8}$ una violencia que se representa en el cuerpo de manera que lo configura y se constituye a partir de este.

De esa manera, Pertuz (2007) señala que el cuerpo se convierte en una herramienta plástica que representa la violencia, una imagen que comunica la realidad de un país como Colombia, por medio de la teatralización (o gesto dramático), convirtiéndose en el escenario de la violencia misma a partir de su representación. La imagen — performances_ posibilita el dar cuenta y la afectación del otro a partir de la expresión de lo violento, poniendo en evidencia la violencia que cotidianamente se ejerce de forma física y psicológica. Así entonces, el cuerpo y el performance se sitúan como imagen, como elemento de testimonio, que manifiesta la inconformidad sobre la violencia que atraviesan los cuerpos de todos los que habitan el país, y no necesariamente han sido partícipes de los actos de barbarie de la guerra.

Como se ha evidenciado, la imagen —el performance — tiene como característica ser un lugar que representa y denuncia desde su componente estético prácticas como la violencia. Sin embargo, tal característica se moviliza a partir de la intencionalidad de afectar las realidades e imaginarios de los otros frente a distintos acontecimientos, en este caso violentos. Así, la imagen se asume entonces como lo que queda en la mente de quien la ve, y hace posible pensar los distintos fenómenos de forma crítica y reflexiva, para construir otras formas de acercarse y habitar el mundo. 
En esta línea, Juan José Correa (2010) en su texto Imágenes del terror en Colombia, analiza el conflicto armado que vivió el país entre 1948 y 1960, en el que las imágenes, ${ }^{9}$ específicamente las fotográficas, no sólo constituyeron objeto de estudio de investigadore ${ }^{10}$ de las causas de la violencia bipartidista, sino que además, como lo afirma el autor, fueron utilizadas por los propios victimarios como medio efectivo para propagar el terror.

Las imágenes creadas por victimarios posteriormente fueron llevadas a las ciudades para ser compartidas en los espacios públicos, con el propósito de sensibilizar a quienes se encontraban geográficamente distantes; además, fueron presentadas a los altos mandos del Estado, con el fin de reconocer de manera oficial el conflicto. De esta manera, las fotografías lograron rescatar la memoria colectiva de las víctimas, configurándose como recurso capaz de producir nuevos discursos y comprensiones sobre los acontecimientos violentos del país.

En esa medida, para Correa (2010) la fotografía se entiende como una serie de

Códigos visuales, que usaban los victimarios para desecrar los cadáveres con una serie de alegorías como los famosos cortes de franela, que servían al ver las imágenes (que los mismos asesinos creaban con una cámara) como una forma inmediata de propagar el terror en los habitantes de las regiones cercanas. (pp. 6-7)

Cabe destacar que el tipo de imágenes a las que se refiere el autor, por un lado proponen miradas particulares, donde se establecen distintas reflexiones en torno al fenómeno de la violencia en Colombia. La imagen fotográfica cumple una función explícita con relación a su eficacia para expandir el terror, "de ahí la insistencia en mostrar fotos donde quedaran evidenciadas las torturas y los asesinatos de mujeres embarazadas, niños y demás población indefensa" (Correa, 2010, p. 10). Las imágenes revelaron ante los otros una historia inédita del terror proponiendo un acercamiento a la fotografía como discurso, en tanto puede ser considerada como un sistema complejo de sentidos que logra expandirse en las comunidades a las que dicho relato ingresaba. Al respecto, Correa menciona que

La imagen fotográfica actuaría entonces como una narración contada con cierta intencionalidad a alguien, a quien le permite acceder — si bien de modo discontinuo - a una realidad pasada susceptible de ser leída en su singularidad. (Correa, 2010, p. 3)

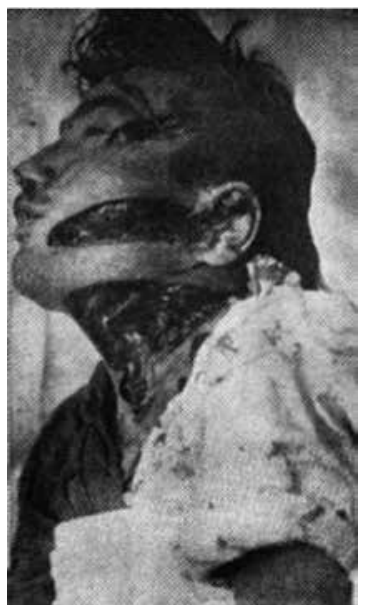

Imagen 3. Autor desconocido, "Corte de Franela". 1962. Colección Guzmán. Fuente: La Violencia en Colombia". 


\section{NOTAS FINALES}

Para finalizar, queremos volver sobre algunas insistencias que pretenden destacar aspectos que por un lado animaron la construcción de este artículo y por otro nos dejan frente a nuevos desafíos de reflexión e investigación en torno a las categorías "imagen" y "violencia", inicialmente propuestas en el estado del arte, y de las que se buscaba encontrar la relación en los textos que se abordaron como corpus documental. No obstante, en ellos se evidencia con mayor fuerza, el trabajo alrededor de la categoría "imagen", razón por la cual este artículo se ha centrado en visibilizar el lugar de esta y su relación con la violencia; de tal manera que se presentó la imagen en su carácter comunicativo, como documento histórico, en relación con el cuerpo y como posibilitadora de la construcción de discursos.

Pese a la clasificación mencionada en los textos documentados, en donde la imagen circula por estas cuatro dimensiones, el grupo de investigación ha identificado, en una lectura interlineal, la existencia de categorías emergentes que posibilitan una comprensión más amplia del vínculo entre la imagen y la violencia, que si bien no son explicitadas por los autores de los textos revisados, surgen de manera reiterativa, por lo cual llaman la atención del grupo durante la puesta en marcha del ejercicio investigativo. Dichas categorías emergentes son: el cuerpo, la historia y el discurso, todas ellas atravesadas por un carácter comunicativo. Cabe aclarar que las categorías emergentes no explican en su totalidad la relación entre las categorías iniciales: imagen y violencia, sino que las relaciones entre todas las categorías -iniciales y emergentes- tienen lugar en puntos de encuentro, lo que nombraremos como nodos subyacentes: ideología, memoria e intención comunicativa.

El nodo ideológico es transversal a las categorías emergentes, pues determina los modos de comprensión de la imagen y la violencia, atribuyéndole a estas una intencionalidad política que se inscribe a su vez en las categorías emergentes; esto es, en lo histórico, en lo discursivo y en lo corporal. Esta intencionalidad política es constitutiva del nodo memoria, y permite que los autores hablen de los acontecimientos violentos a partir de la imagen; en ese sentido, es posible identificar su intención comunicativa, por tanto de ella se puede decir, de la imagen, que nos cuenta acerca de otros modos para comprender la violencia.

Hasta aquí se han evidenciado distintos modos de comprender las relaciones entre la imagen y la violencia, donde esta última se entiende como un elemento que posibilita y da lugar a diferentes reflexiones, pues se sitúa como un fenómeno que directa o indirectamente interpela a artistas, antropólogos, sociólogos e historiadores, y de esa manera logra producir en ellos la urgencia de comunicar los acontecimientos violentos.

La imagen emerge desde los hechos violentos, y en esa medida materializa la violencia desde la expresión artística, posee una pretensión ética y estética, en tanto la imagen y la violencia fundan su vínculo desde la inconformidad, la necesidad del recuerdo, y el esfuerzo por mostrarse, es así que adquiere un carácter comunicativo, que se basa en la veracidad y en la colectividad sobre el pasado. Se trata entonces de una doble connotación de la imagen: como representación y lugar de la memoria. Pero, ¿Qué representa la imagen? ¿En qué medida es un lugar de la memoria? ¿Qué relación se da entre la representación y lo que se memora?

Pues bien, para que la imagen sea un lugar de la memoria, de acuerdo con los postulados de Pierre Nora (s/f), debe tener la intención de recordar, de materializar lo inmaterial, y debe comprender los diferentes sentidos que los sujetos otorgan a lo recordado, para lo cual es preciso un espacio material que permita que el recuerdo de un acontecimiento se manifieste 
de forma colectiva y tenga repercusiones significativas para un grupo determinado, las cuales se dan, como se evidencia en los apartados anteriores, en la medida en la que exista una intencionalidad comunicativa, ideológica e histórica que sea visible, esto es, lo representado en la imagen.

La representación, desde allí, es una forma distinta de comprender y de presentar un fenómeno como la violencia, es la versión que se ofrece sobre un acontecimiento, pero no el acontecimiento en sí mismo; o como lo señala Ranciére (2010):

La representación no es el acto de producir una forma visible, es el acto de dar un equivalente

[...] La imagen no es el doble de una cosa. Es un juego complejo de relaciones entre lo visible

y lo invisible, lo visible y la palabra, lo dicho y lo no dicho. [...] Es siempre una alteración que

toma lugar en una cadena de imágenes que a su vez se altera. (p. 94)

En ese orden de ideas, cabe señalar que la imagen que se muestra desde la perspectiva de los autores trabajados tiene como rasgo característico ser dinámica en el tiempo; sin embargo, adolece de una referencia directa que profundice sobre los nodos que aquí se proponen, como un nuevo escenario de discusión, cuya naturaleza refiere a las potencias del diálogo intercategorial donde se encuentra el efecto de la relación entre imagen y violencia.

Lo anterior se refiere a una imagen que se transforma en la medida en que la época y los sujetos también lo hacen. La imagen posee una historia, pero no es histórica, pues lo que representa y lo que el espectador percibe de ella, dependen del momento determinado en el que se está frente a ella, y de la misma forma, de la singularidad de quien la produce y quien la interpreta. La imagen con relación a la violencia, tiene como rasgo la denuncia, que le atribuye el carácter de testimonio, lo cual procura, sin dejar de lado las particularidades que movilizan su creación, posibilitar otras formas de comprender los acontecimientos, afectar al otro en su condición psicológica y física, pero ante todo, invitarlo a pensar el fenómeno de la violencia.

En suma, se trata de una imagen que con la intención de interpelar a quien la observa, busca de-construir y re-construir los imaginarios que existen sobre las prácticas violentas, y por qué no, también de las prácticas artísticas.

\section{NOTAS}

1 La perspectiva de estado del arte que acoge el grupo de investigación, sitúa el rastreo documental como escenario de posibilidad desde el cual se da cuenta de los diferentes estudios, investigaciones, producciones académicas y artísticas que se han elaborado en torno a las categorías de análisis que se propone el proyecto para su ejecución.

2 Recuperado el 20 de abril del año 2014 en: http://www.elespectador.com/noticias/paz/60-anos-de-un-procesode-paz-articulo-446792.

3 Doris Salcedo. Sin título (1988-1990), Atrabiliarios (1992-1993).

4 https://www.youtube.com/user/CentroMemoriaH/videos

5 https://www.youtube.com/watch?v=das2Pipwp2w\&list=UU-J8xqzoV5ceuoYdFunLEhO

6 Documental en cooperación con Razón Pública. https://www.youtube.com/watch?v=QxpspLU72vE

7 Recuperado el 20 de abril de 2014 en: https://www.google.com.co/search?q=la+violencia+en+martha+rodr 
iguez\&es_sm=93\&source=Inms\&tbm=isch\&sa=X\&ei=vENUU9GKAeLNsOTM2oCYAg\&ved=0CAgQ_AUoA $\mathrm{Q} \& \mathrm{biw}=1366 \& \mathrm{bih}=677 \# \mathrm{q}=$ martha+rodriguez+una+casa+sola+se+vence\&tbm=isch\&facrc=_\&imgdii=_\&im grc=9Z0DF5EVr77JIM\%253A\%3B0ogJckDMpck__M\%3Bhttp\%253A\%252F\%252Fwww.martarodriguez. org\%252Fmartarodriguez.org\%252FUna_Casa_Sola_Se_Vence_(2004)_files\%252Fmarta-palma-web-filtered. jpg\%3Bhttp\%253A\%252F\%252Fwww.martarodriguez.org\%252Fmartarodriguez.org\%252FUna_Casa_Sola_ Se_Vence_(2004).html\%3B151\%3B206

9 La imagen en este texto hace referencia a las fotografías de los asesinatos cometidos por parte de los grupos que estaban en pugna por el territorio político: los liberales y los conservadores. Estas imágenes fueron nombradas por el autor como Imágenes del terror. (Reseña \#2 elaborada por A. Avella Estrada, 2013).

10 Investigadores de la Comisión Nacional Investigadora de las causas actuales de la violencia en Colombia.

11 Recuperado el 20 de abril de 2014 en: http://www.antropologiavisual.cl/imagenes16/imprimir/correa_imp.pdf.

\section{REFERENCIAS}

Asclepio. Mediaciones y lucha de sensibilidades en el arte contemporáneo colombiano. [en línea] http://premionalcritica.uniandes.edu.co/?texto=mediaciones-y-lucha-de-sensibilidades-en-elarte-contemporaneo (Acceso: el 18 de noviembre del 2013)

Correa, J. "Imágenes del terror en Colombia: Reflexiones sobre los documentos fotográficos en escenarios de violencia". Revista Chilena de Antropología Visual, núm. 16 (2010): 119-132.

González, L., Sánchez, L., Conrado, U. Memorias, destierro y reparación. Medellín: Museo de Antioquia, 2008.

Malagón-Kurka, M. M. Arte como presencia indéxica. La obra de tres artistas colombianos en tiempos de violencia: Beatriz González, Oscar Muñoz y Doris Salcedo en la década de los noventa. Bogotá: Universidad de los Andes, 2010.

Merewether, M. "Comunidad y continuidad: Doris Salcedo, nombrando la violencia." Arte en Colombia Internacional, núm. 55 (junio-agosto 1993): 104-109.

Nora, P. Entre memoria e historia: La problemática de los lugares. [En línea] http:// Comisionporlamemoria.Net/Bibliografia2012/Historia/Pierre.Pdf (Acceso: septiembre de 2013).

Ordóñez, L. La historia impronunciable: conflicto armado y cine colombiano después de la Ley de Cine (2013) Revista digital Historik. [En línea] <http://www.revistahistorik.com/> (Acceso: 10 de noviembre de 2013).

Pertuz, F. Performance, arte y violencia en Colombia. [En línea] http://performancelogia.blogspot. com/2007/06/performance-arte-y-violencia-en.html. (Acceso: 20 de noviembre de 2013).

Ranciére. J. “La imagen Intolerable”. En: El espectador emancipado. Buenos Aires: Manantial, 2010.

Silva, S. "La violencia en Colombia: una perspectiva desde el arte". Revista Nodo \# 13. [En línea] http://csifesvr.uan.edu.co:81/index.php/nodo/article/view/162/142 (Acceso: 5 de noviembre de 2013).

Tovar, H. "Entre el color y el terror". Amérique Latine Histoire et Mémoire. Les Cahiers. [En línea] http://alhim.revues.org/768 (Acceso: 23 de noviembre de 2013). 


\section{Cómo citar este artículo:}

Castaño, Etna; Avella, Alejandra; Arango, Alejandra y Sánchez, Carlos. "La imagen en el contexto de la violencia en Colombia: un acercamiento a distintas perspectivas". Cuadernos de Música, Artes Visuales y Artes Escénicas, 11(1), 151-163, 2016. http://dx.doi.org/10.11144/Javeriana.mavae11-1.icvc 
